\title{
Heritabilities of Facial Measurements and Their Latent Factors in Korean Families
}

\author{
Hyun-Jin Kim ${ }^{1,2}{ }^{\dagger}$, Sun-Wha Im ${ }^{1,3,4}{ }^{\text {, Ganchimeg } \text { Jargal }^{5} \text {, Siwoo Lee }}{ }^{6}$, Jae-Hyuk Yi ${ }^{1}$, \\ Jeong-Yeon Park ${ }^{3}$, Joohon Sung, ${ }^{5}$, Sung-Il Cho ${ }^{5}$, Jong-Yeol Kim ${ }^{6}$, \\ Jong-Il Kim ${ }^{1,2,3,4 *}$, Jeong-Sun Seo ${ }^{1,2,3 * *}$ \\ ${ }^{1}$ Genomic Medicine Institute, Medical Research Center, Seoul National University, Seoul 110-799, Korea, \\ ${ }^{2}$ Department of Biomedical Sciences, Seoul National University Graduate School, Seoul 110-799, Korea, \\ ${ }^{3}$ Department of Biochemistry and Molecular Biology, Seoul National University College of Medicine, Seoul 110-799, Korea, \\ ${ }^{4}$ Division of Constitutional Medicine Research, Korea Institute of Oriental Medicine, Daejeon 305-811, Korea, \\ ${ }^{5}$ Psoma Therapeutics, Seoul 153-781, Korea, ${ }^{6}$ Department of Epidemiology, Graduate School of Public Health and Institute of \\ Health and Environment, Seoul National University, Seoul 151-742, Korea
}

\begin{abstract}
Genetic studies on facial morphology targeting healthy populations are fundamental in understanding the specific genetic influences involved; yet, most studies to date, if not all, have been focused on congenital diseases accompanied by facial anomalies. To study the specific genetic cues determining facial morphology, we estimated familial correlations and heritabilities of 14 facial measurements and 3 latent factors inferred from a factor analysis in a subset of the Korean population. The study included a total of 229 individuals from 38 families. We evaluated a total of 14 facial measurements using 2D digital photographs. We performed factor analysis to infer common latent variables. The heritabilities of 13 facial measurements were statistically significant $(p<0.05)$ and ranged from 0.25 to 0.61 . Of these, the heritability of intercanthal width in the orbital region was found to be the highest $\left(h^{2}=0.61, \mathrm{SE}=0.14\right)$. Three factors (lower face portion, orbital region, and vertical length) were obtained through factor analysis, where the heritability values ranged from 0.45 to 0.55 . The heritability values for each factor were higher than the mean heritability value of individual original measurements. We have confirmed the genetic influence on facial anthropometric traits and suggest a potential way to categorize and analyze the facial portions into different groups.
\end{abstract}

Keywords: facial bones, genetic research, statistical factor analysis

\section{Introduction}

In the context of bone morphology, the craniofacial region represents the most complex and special part of the body, consisting of 22 separate bones in addition to 22 deciduous and 32 permanent teeth [1]. Most skull bones are developed from neural crest cells, where the skull vault, mandible, and maxilla are formed from intramembranous ossification in the mesenchyme without cartilage. On the other hand, bones from other parts of body are originated from mesoderm and are formed from endochondral ossification. The human face is made from the fusion of 5 prominences (the fronto-nasal prominence and two pairs of maxillary and mandibular prominences), which occur from the 4 th to 10 th weeks of development, where defects in the process result in many kinds of facial clefts [2].

Studies on human facial morphology can impact various areas, including plastic and dental surgery, facial anatomy, reconstruction, and constitutional diagnosis $[3,4]$, as well as studies on anthropology and genetics. Of these, the implication of genetic factors on facial morphology has been considered important in understanding hereditary disorders as well as tracing the anthropological origin $[5,6]$.

Genetic effects on facial measurements have been inve-

Received May 1, 2013; Revised May 16, 2013; Accepted May 23, 2013

*Corresponding author 1: Tel: +82-2-740-8421, Fax: +82-2-747-8250, E-mail: jongil@snu.ac.kr

**Corresponding author 2: Tel: +82-2-740-8246, Fax: +82-2-741-5423, E-mail: jeongsun@snu.ac.kr

${ }^{\dagger}$ Hyun-Jin Kim and Sun-Wha Im contributed equally to this work.

Copyright (C) 2013 by the Korea Genome Organization

(c) It is identical to the Creative Commons Attribution Non-Commercial License (http://creativecommons.org/licenses/by-nc/3.0/) 
stigated considerably in the past. Several twin studies evaluated the genetic and non-genetic influence on facial traits [7-10]. One classical twin study showed significant genetic variance of alveolar bone height $\left(h^{2}=0.36\right)$ using intraclass correlation between twins $(\mathrm{MZr}=0.70$ and $\mathrm{DZr}=$ 0.52 ) [7]. Another twin study found significant sex differences of genetic variance in anterior face height and no genetic influence on angular measurements [8]. On the other hand, several angle measurements, such as soft-tissue facial angle and Holdaway angle, were shown to have genetic effects [11] in a Turkish Anatolian siblings study.

Family studies, in addition to the twin studies, have reported several key findings regarding the genetic contribution of facial traits [12-17]. In 1991, Kohn [13] found an important role of genetic influence on craniofacial growth. A family study based on ethnically homogeneous Chuvasha pedigrees has found that genetic factors substantially contribute to head shape, where the unadjusted estimates of heritability were found to range from 0.35 to 0.71 [14]. In a recent study using the Hallstatt skull, it was shown that the additive genetic variation accounted for approximately $30 \%$ of the phenotypic variation in total facial dimensions (maximum facial breadth, length, and height) [16]. Familial correlation can also be used as an important indicator to grasp genetic and environmental proportions. A morphological characteristics study based on 125 Belgian families has found evidence of genetic determination in longitudinal body measurements and, to a lesser extent, in soft tissues and in nose or mouth regions [12].

There exist a variety of complex indicators for the measurement of facial size and length. A common characterization of facial measurements by reducing the dimension using factor analysis can be very helpful in understanding the genetics behind facial morphology. In recent years, most studies based on this concept assessed 2 common factors: horizontal components (HOCs) and vertical components (VECs). Several investigations found that the genetic effect was estimated differently between 2 factors $[8,10,14,18$, 19]. In these studies, however, the extraction of common latent variables in facial complex measurements was only limited to HOCs and VECs. In understanding the implication of genetic influence of facial morphology, other characterization methods in addition to the horizontal and vertical component could also be useful.

Although many researchers have studied the genetic effects on facial morphology, most of them have focused on congenital diseases accompanied by facial anomalies. Genetic studies on facial morphology targeting healthy population of various ethnicities are therefore still lagging behind.

The aims of this study were to infer common latent factors by analyzing the pattern found in a factor analysis of 14 facial measurements from the Korean population and investigate the existence of genetic effects for the factors through estimation of familial correlations and heritability.

\section{Methods}

\section{Subjects}

The study was approved and conducted by the Korean Institute of Oriental Medicine (KIOM) from November 1 , 2006 to July 31, 2008. Three local clinical centers and 10 hospitals were recruited for this work. Photographs for facial analysis were taken by trained investigators according to a standard protocol. To ensure the quality of the photographs, we took 2 facial pictures from both the front and the lateral side of each subject and selected the better representative pictures for the analysis. During the first and second phase of this survey, 114 and 164 individuals were collected, respectively. Subjects with poor-quality photographs were excluded from analysis. The study included a total of 229 individuals from 38 families, and of these, one family had a large extended pedigree. All samples were of Korean origin. Anyone who had a facial anomaly or surgery was excluded in this study. The mean and standard deviation (SD) of parents' age were 55.2 and 13.9 , and those of the offspring's age were 36.0 and 17.4, respectively.

\section{Facial measurements}

Digital photographs used for facial measurements have the advantages of obtaining quick and permanent data [20]. To minimize the potential variability in the measurements among different centers, a single digital camera, with a standard protocol, was employed throughout the collection of data. To correct for distance variable, a standard sliding caliper was held by the subjects while taking photographs. The resulting images were sent to KIOM from each center.

Twenty-five landmarks were selected and produced as described [21] using Image J program, an image processing program developed by the National Institutes of Health (NIH) (Fig. 1). Each of these landmarks was recorded as coordinates in this program. A single measurement can be generated, representing the shortest distance between any of the 2 landmark coordinates of choice. Fourteen of such measurements described below were selected, which best represented the facial characteristic [21].

A total of 14 facial measurements in 5 regions (head and face, orbital, nose, mouth, and ears) were evaluated. For the head and face region, 6 measurements (physiognomical height of the face [tr-gn], height of the forehead I [tr-g], special upper face height [g-sn], height of the lower face [sn-gn], width of the face [zy-zy], and width of the mandible [go-go]) were recorded. Three measurements were collected 
from the orbital region: intercanthal width (en-en), binocular width (ex-ex), and length of the eye fissure (en-ex). The nose region had 3 measurements: height of the nose (n-sn), width of the nose (al-al), and nasal protrusion (sn-prn). One measurement each was taken from the mouth and ear regions: width of the mouth (ch-ch) and length of the auricle (sa-sba) (Table 1, Fig. 1).

To minimize intermeasurement bias, all the measure-
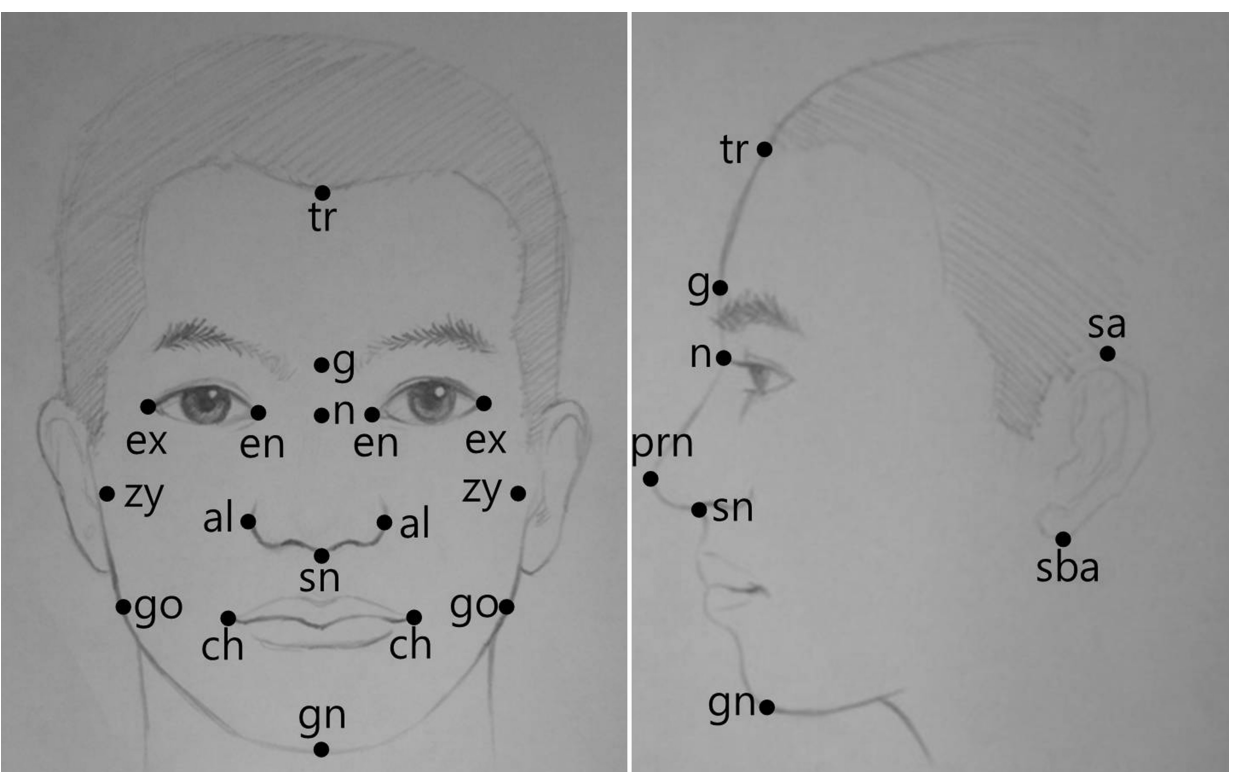

Fig. 1. Twenty five facial landmarks used in this study. al, alare; ch, cheilion; en, endocanthion; ex, exocanthion; g, glabella; gn, gnathion; go, gonion; $\mathrm{n}$, nasion; prn, pronasale; sa, superaurale; sba, subaurale; sn, subna; tr, trichion; zy, zygion.

Table 1. Facial landmarks and measurements in each region

\begin{tabular}{|c|c|c|c|c|}
\hline Region & & Landmarks & Measurements & List description \\
\hline \multirow[t]{6}{*}{ Head and face } & $\begin{array}{l}\operatorname{tr} \\
\text { gn }\end{array}$ & $\begin{array}{l}\text { Trichion } \\
\text { Gnathion }\end{array}$ & tr-gn & Physiognomical height of the face \\
\hline & $\begin{array}{l}\operatorname{tr} \\
\mathrm{g}\end{array}$ & $\begin{array}{l}\text { Trichion } \\
\text { Glabella }\end{array}$ & tr-g & Height of forehead \\
\hline & $\begin{array}{l}\mathrm{G} \\
\text { sn }\end{array}$ & $\begin{array}{l}\text { Glabella } \\
\text { Subnasale }\end{array}$ & g-sn & Special upper face height \\
\hline & $\begin{array}{l}\text { sn } \\
\text { gn }\end{array}$ & $\begin{array}{l}\text { Subnasale } \\
\text { Gnathion }\end{array}$ & sn-gn & Height of the lower face \\
\hline & $\begin{array}{l}\text { zy } \\
\text { zy }\end{array}$ & $\begin{array}{l}\text { Zygion (R) } \\
\text { Zygion (L) }\end{array}$ & $z y-z y$ & Width of the face \\
\hline & $\begin{array}{l}\text { go } \\
\text { go }\end{array}$ & $\begin{array}{l}\text { Gonion (R) } \\
\text { Gonion (L) }\end{array}$ & go-go & Width of the mandible \\
\hline \multirow[t]{3}{*}{ Orbits } & $\begin{array}{l}\text { en } \\
\text { en }\end{array}$ & $\begin{array}{l}\text { Endocanthion (R) } \\
\text { Endocanthion (L) }\end{array}$ & en-en & Intercanthal width \\
\hline & $\begin{array}{l}\text { ex } \\
\text { ex }\end{array}$ & $\begin{array}{l}\text { Exocanthion (R) } \\
\text { Exocanthion (L) }\end{array}$ & ex-ex & Biocular width \\
\hline & $\begin{array}{l}\text { en } \\
\text { ex }\end{array}$ & $\begin{array}{l}\text { Endocanthion } \\
\text { Exocanthion }\end{array}$ & en-ex & Length of the eye fissure \\
\hline \multirow[t]{3}{*}{ Nose } & $\begin{array}{l}\mathrm{n} \\
\mathrm{sn}\end{array}$ & $\begin{array}{l}\text { Nasion } \\
\text { Subnasale }\end{array}$ & n-sn & Height of the nose \\
\hline & $\begin{array}{l}\text { al } \\
\text { al }\end{array}$ & $\begin{array}{l}\text { Alare (R) } \\
\text { Alare (L) }\end{array}$ & al-al & Width of the nose \\
\hline & $\begin{array}{l}\text { sn } \\
\text { prn }\end{array}$ & $\begin{array}{l}\text { Subnasale } \\
\text { Pronasale }\end{array}$ & sn-prn & Nasal protrusion \\
\hline Mouth & $\begin{array}{l}\text { ch } \\
\text { ch }\end{array}$ & $\begin{array}{l}\text { Cheilion (R) } \\
\text { Cheilion (L) }\end{array}$ & ch-ch & Width of the mouth \\
\hline Ears & $\begin{array}{l}\text { sa } \\
\text { sba }\end{array}$ & $\begin{array}{l}\text { Superaurale } \\
\text { Subaurale }\end{array}$ & sa-sba & Length of the auricle \\
\hline
\end{tabular}


ments were taken by a single, well-trained personnel. To verify the robustness and reliability of the measurement method employed herein, we also recorded the intraobserver precision of all 14 measurements on the 20 subsamples, of which age and sex were taken into consideration. The resulting mean intracorrelation coefficient was 0.93 (0.800.99), showing high reliability.

\section{Statistical analysis}

For the calculation of the mean and SD of 14 craniofacial measurements, only individuals with age $\geq 20$ were used to control growth effects. In addition, all genetic analyses for estimating familial correlation and heritability included all age groups.

To estimate the common latent variable in facial measurements, we implemented factor analysis using SAS version 9.1 (SAS Inc., Cary, NC, USA). The eigenvalues for 3 factors were greater than 1 (i.e., the cut-off of the eigenvalue), and the cumulative proportion was $79 \%$. Orthogonal Varimax rotation and principal method were employed. The total number of factors used in this study was 3 . The cut-off value of factor patterns was above $0.6[22,23]$. Before estimating the genetic effects, we calculated 3 factor scores for each individual and evaluated the normal distribution of facial measurements, including factor scores, by QuantileQuantile (Q-Q) plot and Kolmogorov-Smirnov's value. Most Q-Q plot lines were straight, and the measurements tended to follow a normal distribution (Kolmogorov-Smirnov's $\mathrm{p}$ > 0.05).

PEDINFO option in S.A.G.E. (2009; Statistical Analysis for Genetic Epidemiology, Release 6.0.1; http://darwin. cwru.edu/) was used to understand family information, such as offspring $\mathrm{N}$ and sibling $\mathrm{N}$.

Because facial measurements depend on age, sex, and body mass index (BMI) of an individual, we used covariate variables, such as age, sex, age*sex, age2, age2*sex, and BMI. In this modeling, the significant covariate variables were adjusted by screen option of the Sequential Oligogenic Linkage Analysis Routines (SOLAR) package [24]. As a result, the residual variation, which is the remainder of the variation among phenotypes, excluding the portion pertaining to be important covariates, was obtained and applied to approximate the familial correlation and heritability.

We used the FCOR option in S.A.G.E. to estimate familial correlations. Familial correlations were calculated by a set of two random variables $\left(x_{i}, y_{i}\right)_{i=1}^{N}$ and arbitrary weights $\left\{\mathrm{W}_{\mathrm{i}}\right\}$ [25].

$$
\mathrm{r}_{\mathrm{xy}}=\frac{\sum_{i=1}^{N} w_{i}\left(x_{i}-\bar{x}\right)\left(y_{i}-\bar{y}\right)}{\sqrt{\sum_{i=1}^{N} w_{i}\left(x_{i}-\bar{x}\right)^{2} \Sigma_{i=1}^{N} w_{i}\left(y_{i}-\bar{y}\right)^{2}}}
$$

Narrow-sense heritability $\left(h^{2}\right)$ (proportion of phenotype variance attributable to additive genetic variance) was also estimated by maximum likelihood procedure using SOLAR. SOLAR employs a variance-components method, which has a long history in classical genetic study. Additionally, a bivariate model was used to test the genetic correlation between pairs of facial measurements within each factor. We estimated two parameters, based on maximum likelihood ratio method: additive genetic correlation $(\rho \mathrm{G})$ and environmental correlations $(\rho \mathrm{E})$.

\section{Results}

Table 2 presents the sample and pedigree information. The number of total samples used in this study is 229 . The portion of females $(58.95 \%)$ was higher than males $(41.05 \%)$. In the pedigree information, the size of each pedigree ranged from 2 to 94 . One large extended family ( $\mathrm{n}$ $=94$ ) provided great statistical power to estimate the inheritance of facial measurements. The number of parentoffspring and sibling pairs was 412 and 191, respectively. Among sibling pairs, the number of brother-sister pairs was the largest (93 pairs). The number of sister-sister and brother-brother pairs was 54 and 44, respectively.

Basic statistics for the 14 original measurements in males and females are summarized in Table 3 . Only those results with age $\geq 20$ were considered, to account for the variable introduced by age. The mean value for males $(n=79)$ was significantly higher than females $(n=120)$ in all measurements $(\mathrm{p}<0.05)$.

Familial correlations and heritabilities of residual variation, adjusted by significant covariates, are presented in Table 4. The mean contribution of significant covariates was 0.27 and ranged from 0.10 to 0.51 . As shown, the spousal correlations $(p \geq 0.05)$, which represent the impacts of a

Table 2. Sample and pedigree information used in the study

\begin{tabular}{|c|c|c|c|}
\hline & & No. & $\%$ \\
\hline \multicolumn{2}{|c|}{ Sample information } & 229 & \\
\hline \multirow[t]{2}{*}{ Sex } & Male & 94 & 41.05 \\
\hline & Female & 135 & 58.95 \\
\hline \multirow{2}{*}{ Age $(y)$} & $\leq 19$ & 30 & 13.10 \\
\hline & $\geq 20$ & 199 & 86.90 \\
\hline \multicolumn{4}{|c|}{ Pedigree information } \\
\hline \multicolumn{2}{|c|}{ Pedigree $\mathrm{N}$} & 38 & \\
\hline & $\begin{array}{l}\text { Mean size per } \\
\text { pedigree (range) }\end{array}$ & 6.19 (min, & $2 ; \max , 94)$ \\
\hline & Parent/Offspring & 412 & \\
\hline & Sibling & 191 & \\
\hline & Sister/Sister & 54 & \\
\hline & Brother/Brother & 44 & \\
\hline & Brother/Sister & 93 & \\
\hline
\end{tabular}


Table 3. Mean and SD of craniofacial measurements of adults age $\geq 20$

\begin{tabular}{llrrr}
\hline & & \multicolumn{3}{c}{ Craniofacial measurement (mm) } \\
\cline { 3 - 5 } & & Male $(\mathbf{n}=\mathbf{7 9 )}$ & Female $(\mathbf{n}=\mathbf{1 2 0})$ & Total $(\mathbf{n}=\mathbf{1 9 9})$ \\
\hline tr-gn & Physiognomical height of the face & $199.1(9.7)$ & $188.9(9.5)$ & $193.0(10.8)$ \\
tr-g & Height of forehead I & $57.5(5.8)$ & $55.4(6.8)$ & $56.2(6.5)$ \\
g-sn & Special upper face height & $70.4(5.0)$ & $67.2(4.5)$ & $68.5(4.9)$ \\
sn-gn & Height of the lower face & $71.4(5.3)$ & $66.4(4.4)$ & $68.4(5.4)$ \\
zy-zy & Width of the face & $140.0(6.3)$ & $133.9(5.5)$ & $136.3(6.6)$ \\
go-go & Width of the mandible & $127.3(8.9)$ & $119.5(7.2)$ & $122.6(8.8)$ \\
en-en & Intercanthal width & $37.9(2.9)$ & $36.8(3.1)$ & $37.3(3.1)$ \\
ex-ex & Biocular width & $90.4(5.2)$ & $87.1(5.3)$ & $88.4(5.5)$ \\
en-ex & Length of the eye fissure & $26.4(1.9)$ & $25.3(1.8)$ & $25.7(1.9)$ \\
n-sn & Height of the nose & $50.5(3.6)$ & $47.0(3.6)$ & $48.4(4.0)$ \\
al-al & Width of the nose & $42.7(2.5)$ & $39.2(2.7)$ & $40.6(3.1)$ \\
sn-prn & Nasal protrusion & $21.3(2.4)$ & $19.5(1.9)$ & $20.2(2.3)$ \\
ch-ch & Width of the mouth & $49.2(3.0)$ & $47.2(3.6)$ & $48.0(3.5)$ \\
sa-sba & Length of the auricle & $71.2(5.6)$ & $65.6(6.1)$ & $67.8(6.5)$ \\
\hline
\end{tabular}

Values are presented as mean (SD).

Table 4. Familial correlations and heritabilities of facial measurements

\begin{tabular}{|c|c|c|c|c|c|c|}
\hline & \multicolumn{3}{|c|}{ Correlations (SE) ${ }^{\mathrm{a}}$} & \multicolumn{3}{|c|}{ Polygenic additive model } \\
\hline & $\begin{array}{c}\text { Parent- } \\
\text { offspring }\end{array}$ & Sibling & Spouse & $h^{2}(\mathrm{SE})^{\mathrm{a}}$ & $\begin{array}{l}\text { Significant } \\
\text { covariates }\end{array}$ & $\begin{array}{c}\text { Covariates } \\
\text { contribution }\end{array}$ \\
\hline tr-gn & $0.23(0.08)$ & $0.08(0.11)$ & $0.12(0.14)$ & $0.32(0.13)$ & Age, sex, age*sex, age ${ }^{2}$ & 0.23 \\
\hline tr-g & $0.25(0.08)$ & $0.13(0.12)$ & $0.13(0.14)$ & $0.31(0.13)$ & Age*sex & 0.12 \\
\hline g-sn & $0.21(0.07)$ & $0.02(0.10)$ & $0.05(0.14)$ & $0.37(0.14)$ & Age, sex, age*sex & 0.13 \\
\hline sn-gn & $0.14(0.08)$ & $0.14(0.11)$ & $0.10(0.14)$ & $0.25(0.14)$ & Age, sex, age ${ }^{2}, B M I$ & 0.37 \\
\hline$z y-z y$ & $0.17(0.07)$ & $0.18(0.12)$ & $0.02(0.31)$ & $0.41(0.16)$ & Age, sex, age*sex age ${ }^{2}, \mathrm{BMI}$ & 0.27 \\
\hline go-go & $0.13(0.14)$ & $0.30(0.13)$ & $0.36(0.19)$ & $0.42(0.12)$ & Sex, age $^{2}$, age $^{2 *}$ sex, BMl & 0.43 \\
\hline en-en & $0.22(0.08)$ & $0.30(0.16)$ & $-0.08(0.14)$ & $0.61(0.14)$ & Age, sex & 0.10 \\
\hline ex-ex & $0.18(0.07)$ & $0.18(0.14)$ & $-0.31(0.26)$ & $0.43(0.16)$ & Age, sex, age ${ }^{2}, \mathrm{BMI}$ & 0.34 \\
\hline en-ex & $0.05(0.12)$ & $0.08(0.11)$ & $-0.20(0.13)$ & $0.28(0.16)$ & Age, sex, age ${ }^{2}, \mathrm{BMI}$ & 0.28 \\
\hline$n-s n$ & $0.21(0.07)$ & $0.00(0.10)$ & $0.09(0.14)$ & $0.33(0.14)$ & Age, sex, age* sex & 0.18 \\
\hline al-al & $0.35(0.07)$ & $0.25(0.20)$ & $0.04(0.25)$ & $0.53(0.13)$ & Age, sex, age ${ }^{2}, \mathrm{BMI}$ & 0.51 \\
\hline sn-prn & $0.32(0.09)$ & $0.43(0.14)$ & $0.23(0.13)$ & $0.44(0.11)$ & Sex, age $^{2}$ & 0.15 \\
\hline ch-ch & $-0.03(0.09)$ & $0.24(0.14)$ & $0.23(0.13)$ & $0.23(0.15)$ & Age, sex, age ${ }^{2}$ & 0.38 \\
\hline sa-sba & $0.27(0.16)$ & $0.34(0.13)$ & $0.06(0.14)$ & $0.37(0.13)$ & Age, sex, BMI & 0.29 \\
\hline
\end{tabular}

Significant correlation coefficient values and heritabilities are marked in bold $(p<0.05)$.

$\mathrm{SE}$, standard error; BMI, body mass index.

${ }^{a}$ Familial correlation and heritability were calculated by residual variation after adjusting for significant covariates.

common environment and partially assortative mating, were lower than the other correlations in most measurements. Except for height of the lower face (sn-gn), width of the mandible (go-go), length of the eye fissure (en-ex), width of the mouth (ch-ch), and length of the auricle (sa-sba), the correlations between parent and offspring were statistically significant ( $p<0.05$ ). The correlations between siblings were statistically significant for width of the mandible (go-go), nasal protrusion (sn-prn), and length of the auricle (sa-sba). The heritabilities of 13 facial measurements, except for width of the mouth (ch-ch), were statistically significant $(p<0.05)$ and ranged from 0.25 to 0.61 . The heritability of intercanthal width (en-en) in the orbital region was found to be the highest $\left(h^{2}=0.61, \mathrm{SE}=0.14\right)$, whereas in the nose region, width of the nose (al-al) showed the highest heritability $\left(h^{2}=0.53, \mathrm{SE}=0.13\right)$.

Table 5 shows the pattern of rotated factors by factor analysis with 14 facial measurements. We obtained 3 factors whose eigenvalue was greater than 1 . Factors were denoted according to loading scores of rotated factors above 0.6 [22, 23]. Factor 1 included 4 measurements: height of the lower face (sn-gn), width of the mandible (go-go), width of the 
Table 5. Factor analysis of 14 facial measurements

\begin{tabular}{llccc}
\hline & \multicolumn{1}{c}{ Measurements } & Factor $\mathbf{1}$ & Factor 2 & Factor 3 \\
\hline tr-gn & Physiognomical height of the face & 0.40589 & 0.45897 & $\mathbf{0 . 6 9 2 4 9}$ \\
tr-g & Height of forehead I & -0.30659 & 0.57181 & 0.47891 \\
g-sn & Special upper face height & 0.30720 & 0.00712 & $\mathbf{0 . 8 5 6 9 4}$ \\
sn-gn & Height of the lower face & $\mathbf{0 . 8 2 5 6 8}$ & 0.21648 & 0.06208 \\
zy-zy & Width of the face & 0.58795 & 0.54025 & 0.15421 \\
go-go & Width of the mandible & $\mathbf{0 . 6 1 8 4 1}$ & 0.37137 & 0.13134 \\
en-en & Intercanthal width & 0.05016 & $\mathbf{0 . 6 4 9 9 6}$ & 0.23795 \\
ex-ex & Biocular width & 0.24531 & $\mathbf{0 . 9 2 3 5 0}$ & 0.06526 \\
en-ex & Length of the eye fissure & 0.27891 & $\mathbf{0 . 8 0 0 1 5}$ & -0.07688 \\
n-sn & Height of the nose & 0.38053 & 0.12779 & $\mathbf{0 . 7 4 0 9 0}$ \\
al-al & Width of the nose & $\mathbf{0 . 7 2 9 3 3}$ & 0.11054 & 0.19756 \\
prn-sn & Nasal protrusion & 0.51047 & 0.16059 & 0.26711 \\
ch-ch & Width of the mouth & $\mathbf{0 . 6 0 5 8 2}$ & 0.02424 & 0.14614 \\
sa-sba & Length of the auricle & 0.59098 & -0.00701 & 0.24333 \\
Explained variance & of total variance & $35.6 \%$ & $29.8 \%$ & $22.9 \%$ \\
\hline
\end{tabular}

Values of loading score of rotated factors above 0.6 are marked in bold.

Factor 1 includes measurements of the lower face, Factor 2 includes measurements of the orbit region, and Factor 3 includes vertical measurements related to facial height.

Table 6. Familial correlations and heritabilities of factor variables

\begin{tabular}{|c|c|c|c|c|c|}
\hline \multirow{2}{*}{\multicolumn{2}{|c|}{ Correlations $^{\mathrm{a}}$ (relationship) }} & & \multicolumn{3}{|c|}{ Polygenic additive model } \\
\hline & & & \multirow[t]{2}{*}{$h^{2}(\mathrm{SE})^{\mathrm{a}}$} & Significant covariates & \multirow{2}{*}{$\begin{array}{c}\text { Covariates contribution } \\
0.58\end{array}$} \\
\hline Factor 1 & Parent-offspring & $0.34(0.08)$ & & Age, sex, age $^{2}$, Age $^{2 *}$ sex, BMI & \\
\hline & Sibling & $0.34(0.13)$ & & & \\
\hline & Spouse & $0.15(0.13)$ & $0.55(0.12)$ & & \\
\hline \multirow[t]{3}{*}{ Factor 2} & Parent-offspring & $0.15(0.12)$ & & Age, sex, age ${ }^{2}, \mathrm{BMI}$ & 0.36 \\
\hline & Sibling & $0.17(0.12)$ & & & \\
\hline & Spouse & $-0.26(0.29)$ & $0.52(0.15)$ & & \\
\hline \multirow[t]{3}{*}{ Factor 3} & Parent-offspring & $0.15(0.15)$ & & Age, sex, age*sex, Age $^{2}, \mathrm{BMI}$ & 0.15 \\
\hline & Sibling & $0.09(0.11)$ & & & \\
\hline & Spouse & $0.22(0.27)$ & $0.45(0.13)$ & & \\
\hline
\end{tabular}

Significant correlation coefficient values and heritability are marked in bold ( $p<0.05$ ).

$\mathrm{SE}$, standard error; BMI, body mass index.

${ }^{\mathrm{a}}$ Familial correlation and heritability were calculated by residual variation after adjusting for significant covariates.

nose (al-al), and width of the mouth (ch-ch). Factor 2 included intercanthal width (en-en), biocular width (ex-ex), and length of the eye fissure (en-ex), which were related to the orbital region. Factor 3 included physiognomical height of the face (tr-gn), special upper face height (g-sn), and height of the nose (n-sn). The familial correlations and heritabilities of 3 factors are shown in Table 6. In Factor 1, the correlation of spouse ( $p \geq 0.05$ ) was lower than that of parent-offspring and sibling pairs, whereas meaningful familial correlations were not found in Factor 2 or Factor 3. The heritabilities of 3 factors were statistically significant ( $p$ $<0.05$ ) and ranged from 0.45 to 0.55 . Factor 1 , which was related to the lower face, had the highest value for heritability $\left(h^{2}=0.55, \mathrm{SE}=0.12\right)$.
Using a bivariate model, we examined genetic correlations for all pairs within each factor (Table 7). There were several pairs with a statistically significant genetic correlation ( $\mathrm{p} \leq$ 0.05): the pair of height of the lower face (sn-gn) and width of the nose (al-al) ( $\rho \mathrm{G}=0.79, \mathrm{SE}=0.23$ ) for Factor 1 , the pair of intercanthal width (en-en) and biocular width (ex-ex) ( $\rho \mathrm{G}=0.82, \mathrm{SE}=0.08$ ) and the pair of biocular width (ex-ex) and length of the eye fissure (en-ex) ( $\rho \mathrm{G}=0.81$, SE $=0.09$ ) for Factor 2, and the pair of physiognomical height of the face (tr-gn) and special upper face height (g-sn) ( $\rho \mathrm{G}$ $=0.74, \mathrm{SE}=0.17)$ and the pair of special upper face height (g-sn) and height of the nose (n-sn) $(\rho \mathrm{G}=0.98, \mathrm{SE}=0.06)$ for Factor 3. 
Table 7. Genetic and environmental correlations for pairs of facial-related measurements

\begin{tabular}{llcccc}
\hline & & \multicolumn{2}{c}{$\begin{array}{c}\text { Genetic } \\
\text { correlation }\end{array}$} & \multicolumn{2}{c}{$\begin{array}{c}\text { Environmental } \\
\text { correlation }\end{array}$} \\
\cline { 3 - 6 } & & $\rho$ Bivariate & SE & $\rho$ E & SE \\
\hline Factor 1 & sn-gn, go-go & 0.26 & 0.25 & $\mathbf{0 . 4 0}$ & 0.13 \\
& sn-gn, al-al & $\mathbf{0 . 7 9}$ & 0.23 & 0.03 & 0.16 \\
& sn-gn, ch-ch & 0.75 & 0.48 & 0.15 & 0.13 \\
& go-go, al-al & 0.26 & 0.19 & $\mathbf{0 . 3 9}$ & 0.15 \\
& go-go, ch-ch & 0.18 & 0.30 & 0.20 & 0.14 \\
& al-al, ch-ch & 0.48 & 0.27 & $\mathbf{0 . 4 2}$ & 0.14 \\
Factor 2 2 & en-en, ex-ex & $\mathbf{0 . 8 2}$ & 0.08 & $\mathbf{0 . 6 1}$ & 0.13 \\
& en-en, en-ex & 0.32 & 0.22 & 0.04 & 0.20 \\
& ex-ex, en-ex & $\mathbf{0 . 8 1}$ & 0.09 & $\mathbf{0 . 8 1}$ & 0.07 \\
Factor 3 3 & tr-gn, g-sn & $\mathbf{0 . 7 4}$ & 0.17 & $\mathbf{0 . 5 2}$ & 0.10 \\
& tr-gn, n-sn & 0.63 & 0.21 & $\mathbf{0 . 5 5}$ & 0.10 \\
& g-sn, n-sn & $\mathbf{1 . 0 0}$ & - & $\mathbf{0 . 7 1}$ & 0.06 \\
\hline
\end{tabular}

$\mathrm{SE}$, standard error.

Significant genetic and environmental correlation are marked in bold $(p<0.05)$.

\section{Discussion}

There are several distinctive features of facial morphology found in Koreans compared to western populations. First, the nose of Koreans tends to be relatively shorter and broader than that found in Italians [26], Caucasians [27], and Latvian [28] populations. Koreans also have a relatively narrower face (zy-zy) and wider mandible (go-go), and eyes (en-ex) when compared to Italians and wider intercanthal width (en-en), narrower width of the mouth (ch-ch), and longer special upper face height (g-sn) and length of the auricle (sa-sba) than Caucasians. Compared to Latvians, Koreans have broader (zy-zy and go-go) and longer (tr-gn) faces, narrower binocular width (ex-ex) and length of the eye fissure (en-ex), and wider intercanthal width (en-en).

The heritabilities that were significant for 13 phenotypes had a wide range of values $\left(h^{2}=0.25-0.61\right)$. Previous papers have reported estimated heritabilities of craniofacial anthropometric traits, and the results have been in agreement with ours. In one study based on an Indian population, the heritabilities of nasal height and breadth were 0.42 and 0.50; in addition, that of facial height and bizygomatic breadth were 0.41 and 0.61 [29]. Another study enrolling a Chuvasha pedigree reported that the heritabilities of nasal height, physiognomic facial height, bizygomatic breadth, and bigonial breadth were $0.42,0.38,0.58$, and 0.50 , respectively [14]. The other paper targeting orbital traits of Brazilians reported that the heritabilities of intercanthal width, biocular width, and length of the eye fissure were $0.39,0.34$, and 0.51 [30]. Recently, we reported the herita- bilities and suggestive genetic loci associated with ocular and nasal traits in an isolated Mongolian population [31]. The heritabilities in Mongolians $\left(h^{2}=0.48-0.90\right)$ were slightly higher than those of Koreans $\left(h^{2}=0.25-0.61\right)$. The difference between the two populations can be explained by the low level of genetic heterogeneity and environmental effects in the isolated population model.

Several groups have reported that vertical facial variables displayed greater genetic effects than horizontal facial variables [8, 9, 32]. However, another group has challenged this by presenting an opposite result, although it was found not to be statistically significant [14]. The results obtained in our study support for a greater genetic effect of the horizontal craniofacial variables, where vertical variables (tr-gn, tr-g, g-sn, and sn-gn) displayed less heritability than the horizontal variables (zy-zy and go-go). A similar pattern was also observed for the nose region.

We were able to identify 3 latent factors related to facial measurements through factor analysis (Table 5). Factor 2 showed relation to the orbital region: intercanthal width (en-en), biocular width (ex-ex), and length of the eye fissure (en-ex). When we consider the early development of the face, there are very unique processes for making eyes and orbits. Factor 2 may be related with one of the common regulators controlling these processes. Factor 3 included vertical length values in the upper face region (special upper face height [g-sn] and height of the nose [n-sn], and physiognomical height of the face [tr-gn]). Because all three values are related with vertical length of the nose (n-sn), this factor may be related with the early developmental process of the nose from the lateral and/or medial nasal prominence. Factor 1 was mainly related to the lower portion of the faceheight of the lower face (sn-gn), width of the mandible (go-go), width of the nose (al-al), and width of the mouth (ch-ch) and this part was made from the maxillary and mandibular prominences of the first pharyngeal arch. However, there remains the possibility that Factor 1 is related with a general factor rather than a specific regulator, because 7 of the 14 measurement values had loading scores above or very close to 0.6 .

Such findings are indicative of a necessity to categorize each facial portion into different classes to improve our understanding of facial genetics. In previous studies, however, the concept of factor analysis in the genetic study of facial morphology was mainly confined to horizontal and vertical measures. Hence, this new concept of facial regions in the current report may provide significant insight into the genetic study of facial morphology.

Factors that are explained by a common facial variable can have a higher genetic variance than each facial measurement [33]. Factor 1, related to the lower face, also indicated the 
highest genetic variance $\left(h^{2}=0.55, \mathrm{SE}=0.12\right)$, which was significantly higher than the mean of each trait (mean $h^{2}=$ 0.36). The estimated heritabilities for Factor 2 and Factor 3 also showed a similar trend $\left(h^{2}=0.52, \mathrm{SE}=0.15\right.$; mean $h^{2}$ $=0.44$ and $h^{2}=0.45, \mathrm{SE}=0.13$; mean $h^{2}=0.34$, respectively) (Table 6). They suggest that the factors reflect the genetic effect well than when compared to each original measurement in the regions.

Additionally, this study employed a bivariate model to investigate shared genetic effects for all pairs of facial measurements within each factor. We estimated the genetic and environment correlations and found 5 pairs with a statistically significant genetic correlation: 1 for Factor 1 and 2 each for Factor 2 and Factor 3. The significant genetic correlation ranged from 0.74 to 1.00 , which suggested that there exists a large genetic portion simultaneously affecting facial measurements in each factor.

To date, various study designs have been employed for identifying the genetic effects of a specific trait where, in general, family, twin, or sibling designs were preferentially chosen. Amongst these three, the family design has many advantages. Firstly, familial correlation and relative risk can be estimated [34]. Secondly, a family study is likely to increase statistical power for finding causative genes and inheritance modes [35] where, especially, a large expended pedigree provides sufficient evidence of linkage as well as maximum statistical power [36].

A variety of methods for measuring facial length or size have been introduced by many researchers [37]. Simple and direct measurement using calipers takes a lot of time and effort and has the probability of incorporating errors between different observers. Another method of facial measurement is radiographic cephalometry, which has the advantage of observing hard tissue, such as bones, but this method is not suited for facial morphology, since it requires high cost and is time-consuming and is thus not suited for large-scale epidemiology. An alternative method used in this study was $2 \mathrm{D}$ digital photography. Although this method is difficult to locate bony structures under the skin, which is necessary to determine facial landmarks as well as measure curved surfaces, this has several advantages. The pictures are quickly obtainable and the measurements can be permanently stored. Observers can be trained easily for precise and unbiased measurement. Radiographic cephalometry is selected for clinical patient care, whereas photographic method is better for investigating facial morphology in a large epidemiological study [20], thereby suggesting that each method for facial measurement should be chosen to fit the purpose of the study; we found our choice of photographic method to be reliable and useful in our study.

Our study has several new aspects and advantages: we provide the first reliable data for facial morphology for the Korean population; we tried a new approach to study faces using factor analysis; and the family data containing a large extended pedigree used in this study provided high statistical power for estimating heritability. Yet, this study is not without caveats. The most obvious limitation in this study is the small sample size. Since the number of subjects was not large enough, the familial correlations between first-degree relatives, especially most sibling pairs, might not have been statistically significant. In our results, the familial correlations of parent-offspring pairs were relatively more significant than those of sibling pairs (Table 4). This is probably due to a relatively small number of sibling pairs than parent-offspring pairs. For the heritability estimation of the 14 phenotypes, the value for width of the mouth (ch-ch) was found to be the smallest and not statistically significant. This may be due to the change in facial expression while taking photographs (emotion or tension), causing variability in width of the mouth (ch-ch). Facial tension created during unusual situations, such as while taking photographs, can influence the measurements, especially for the width of mouth, because of the likelihood for this region to be affected by psychological tension compared to other measurement parts. In addition, we were not able to provide enough data for each age in children, which is an important basis for the diagnosis of congenital facial anomalies.

In conclusion, we have verified the genetic effect on facial anthropometric traits and suggested a potential way to categorize and analyze the facial portions into different groups. Despite many reports on congenital diseases with accompanying facial anomalies, the understanding of common genetic mechanisms, including specific genes that determine the facial morphology in general healthy populations, is still obscure. Our report is a step towards understanding this. Validation with the results of other studies involving varying populations, in addition to studies on genetic linkage association or biologic studies, is warranted for furthering our understanding of this subject.

\section{Acknowledgments}

This research was supported by a Basic Science Research Program through the National Research Foundation of Korea (NRF), funded by the Ministry of Education (No. 2006-2005173). This project was funded by grants from the Korea Health technology R\&D Project, Ministry of Health \& Welfare, Republic of Korea (A101903). 


\section{References}

1. Wilkie AO, Morriss-Kay GM. Genetics of craniofacial development and malformation. Nat Rev Genet 2001;2:458-468.

2. Schoenwolf GC, Larsen WJ. Larsen's Human Embryology. 4th ed. Philadelphia: Churchill Livingstone/Elsevier, 2009.

3. Do JH, Jang E, Ku B, Jang JS, Kim H, Kim JY. Development of an integrated Sasang constitution diagnosis method using face, body shape, voice, and questionnaire information. BMC Complement Altern Med 2012;12:85.

4. Do JH, Ku B, Jang JS, Kim H, Kim JY. Analysis of Sasang constitutional types using facial features with compensation for photographic distance. Integr Med Res 2012;1:26-35.

5. Ding YC, Wooding S, Harpending HC, Chi HC, Li HP, Fu YX, et al. Population structure and history in East Asia. Proc Natl Acad Sci U S A 2000;97:14003-14006.

6. Gad A, Laurino M, Maravilla KR, Matsushita M, Raskind WH. Sensorineural deafness, distinctive facial features, and abnormal cranial bones: a new variant of Waardenburg syndrome? Am J Med Genet A 2008;146A:1880-1885.

7. Michalowicz BS, Aeppli DP, Kuba RK, Bereuter JE, Conry JP, Segal NL, et al. A twin study of genetic variation in proportional radiographic alveolar bone height. J Dent Res 1991; 70:1431-1435.

8. Carels C, Van Cauwenberghe N, Savoye I, Willems G, Loos R, Derom C, et al. A quantitative genetic study of cephalometric variables in twins. Clin Orthod Res 2001;4:130-140.

9. Naini FB, Moss JP. Three-dimensional assessment of the relative contribution of genetics and environment to various facial parameters with the twin method. Am J Orthod Dentofacial Orthop 2004;126:655-665.

10. Amini F, Borzabadi-Farahani A. Heritability of dental and skeletal cephalometric variables in monozygous and dizygous Iranian twins. Orthod Waves 2009;68:72-79.

11. Baydaş B, Erdem A, Yavuz I, Ceylan I. Heritability of facial proportions and soft-tissue profile characteristics in Turkish Anatolian siblings. Am J Orthod Dentofacial Orthop 2007; 131:504-509.

12. Susanne C. Genetic and environmental influences on morphological characteristics. Ann Hum Biol 1975;2:279-287.

13. Kohn LA. The role of genetics in craniofacial morphology and growth. Annu Rev Anthropol 1991;20:261-278.

14. Ermakov S, Kobyliansky E, Livshits G. Quantitative genetic study of head size related phenotypes in ethnically homogeneous Chuvasha pedigrees. Ann Hum Biol 2005;32:585-598.

15. Johannsdottir B, Thorarinsson F, Thordarson A, Magnusson TE. Heritability of craniofacial characteristics between parents and offspring estimated from lateral cephalograms. Am J Orthod Dentofacial Orthop 2005;127:200-207.

16. Martínez-Abadías N, Esparza M, Sjøvold T, González-José R, Santos M, Hernández M. Heritability of human cranial dimensions: comparing the evolvability of different cranial regions. J Anat 2009;214:19-35.

17. Alkhudhairi TD, Alkofide EA. Cephalometric craniofacial features in Saudi parents and their offspring. Angle Orthod 2010; 80:1010-1017.

18. Karmakar B, Ermakov S, Yakovenko K, Kobyliansky E. Genetic determination of head-size-related anthropometric traits in an ethnically homogeneous sample of 373 Indian pedigrees of West Bengal. Hum Biol 2007;79:501-514.

19. Jelenkovic A, Poveda A, Susanne C, Rebato E. Contribution of genetics and environment to craniofacial anthropometric phenotypes in Belgian nuclear families. Hum Biol 2008;80: 637-654.

20. Zhang X, Hans MG, Graham G, Kirchner HL, Redline S. Correlations between cephalometric and facial photographic measurements of craniofacial form. Am J Orthod Dentofacial Orthop 2007;131:67-71.

21. Farkas LG. Anthropometry of the Head and Face. New York: Raven Press, 1994.

22. Sharma S. Applied Multivariate Techniques. New York: John Wiley and Sons Inc., 1996.

23. Cheung WY, Le LW, Zimmermann C. Symptom clusters in patients with advanced cancers. Support Care Cancer 2009;17: 1223-1230.

24. Almasy L, Blangero J. Multipoint quantitative-trait linkage analysis in general pedigrees. Am J Hum Genet 1998;62: 1198-1211.

25. Keen KJ, Elston RC. Robust asymptotic sampling theory for correlations in pedigrees. Stat Med 2003;22:3229-3247.

26. Ferrario VF, Sforza C, Miani A, Tartaglia G. Craniofacial morphometry by photographic evaluations. Am J Orthod Dentofacial Orthop 1993;103:327-337.

27. Weinberg SM, Scott NM, Neiswanger K, Brandon CA, Marazita ML. Digital three-dimensional photogrammetry: evaluation of anthropometric precision and accuracy using a Genex 3D camera system. Cleft Palate Craniofac J 2004;41: 507-518.

28. Nagle E, Teibe U, Kapoka D. Craniofacial anthropometry in a group of healthy Latvian residents. Acta Med Litu 2005;12: 47-53.

29. Arya R, Duggirala R, Comuzzie AG, Puppala S, Modem S, Busi $\mathrm{BR}$, et al. Heritability of anthropometric phenotypes in caste populations of Visakhapatnam, India. Hum Biol 2002;74:325344.

30. Raposo-do-Amaral CM, Krieger H, Cabello PH, Beiguelman B. Heritability of quantitative orbital traits. Hum Biol 1989; 61:551-557.

31. Im SW, Kim HJ, Lee MK, Yi JH, Jargal G, Sung J, et al. Genome-wide linkage analysis for ocular and nasal anthropometric traits in a Mongolian population. Exp Mol Med 2010; 42:799-804.

32. Manfredi C, Martina R, Grossi GB, Giuliani M. Heritability of 39 orthodontic cephalometric parameters on MZ, DZ twins and MN-paired singletons. Am J Orthod Dentofacial Orthop 1997;111:44-51.

33. Hauspie RC, Susanne C, Defrise-Gussenhoven E. Testing for the presence of genetic variance in factors of face measurements of Belgian twins. Ann Hum Biol 1985;12:429-440.

34. Hopper JL, Bishop DT, Easton DF. Population-based family studies in genetic epidemiology. Lancet 2005;366:1397-1406.

35. Borecki IB, Province MA. Genetic and genomic discovery using family studies. Circulation 2008;118:1057-1063.

36. Fuller SJ, Papaemmanuil E, McKinnon L, Webb E, Sellick GS, 
Dao-Ung LP, et al. Analysis of a large multi-generational family provides insight into the genetics of chronic lymphocytic leukemia. Br J Haematol 2008; 142:238-245.
37. Allanson JE. Objective techniques for craniofacial assessment: what are the choices? Am J Med Genet 1997;70:1-5. 